\title{
PENERAPAN METODE PERMAINAN DALAM UPAYA MENINGKATKAN AKTIFITAS BELAJAR DAN HASIL BELAJAR MAHASISWA PADA MATA KULIAH ANATOMI DAN FISIOLOGI MANUSIA
}

\author{
Relsas Yogica ${ }^{1}$, Elsa Yuniarti ${ }^{2}$ \\ Dosen Jurusan Biologi FMIPA Universitas Negeri Padang \\ relsasyogica.1103992@gmail.com
}

\begin{abstract}
Abstrak - Mutu pendidikan menjadi hal yang semestinya diperhatikan oleh pendidik, terutama untuk kelas yang menjadi tanggung jawabnya. Mutu tersebut hanya akan diperoleh saat pendidik mampu mengamati gejala yang terjadi sehingga masalah dapat diselesaikan. Peneliti telah melakukan penelitian tentang dampak metode permainan di Program Studi Biologi FMIPA UNP pada Semester JanuariJuni 2016 pada mata kuliah Anatomi dan Fisiologi Manusia. Penerapan metode ini merupakan inovasi yang layak untuk dicoba karena akan menciptakan suasana belajar yang menyenangkan sehingga nantinya aktifitas dan hasil belajar mahasiswa akan menjadi baik. Peneliti telah menemukan data bahwa aktifitas belajar mahasiswa terus meningkat selama pelaksanaan metode permainan ini, dan pada akhir perkuliahan diperoleh data nilai hasil belajar pada dominansi $\mathrm{B}+$. Kesimpulan penelitian ini adalah metode permainan yang dilaksanakan telah meningkatkan aktifitas dan hasil belajar mahasiswa.
\end{abstract}

Kata Kunci : Metode Permainan, Aktifitas Belajar, Hasil Belajar

\section{PENDAHULUAN}

Upaya pertama yang dilakukan untuk perbaikan mutu pendidikan adalah pemahaman tentang keadaan proses pembelajaran yang sedang terjadi. Pemahaman ini didasarkan pada pengamatan yang dilakukan oleh guru/ dosen terhadap siswa/ mahasiswa. Pengamatan tersebut dilakukan dengan tujuan untuk mengetahui bagaimana kondisi terkini pada sekelompok pembelajar. Pengamatan rutin terhadap kondisi terkini siswa/ mahasiswa penting dilakukan karena akan memberikan informasi akurat tentang masalah yang sedang atau akan muncul. Hasil pengamatan 
dapat dijadikan landasan untuk memberikan solusi guna perbaikan dan penyempurnaan.

Penulis sebagai pengampu mata kuliah Anatomi dan Fisiologi Manusia untuk kelas Program Studi Biologi 2013 telah melakukan pengamatan pada keadaan dan bentuk gaya belajar mahasiswa selama kurang lebih dua minggu. Indikator pengamatan adalah semua aspek yang menjadi aspek evaluasi, yakni aspek afektif, kognitif dan psikomotor. Meski hanya dilakukan selama dua minggu, namun masing-masing mahasiswa telah menunjukkan bentuk kebosanan dalam pembelajaran. Misalnya mahasiswa terlihat mengantuk, sering keluar masuk kelas, menggunakan HP selama perkuliahan bahkan ada mahasiswa yang tertidur di kelas.

Metode perkuliahan yang digunakan adalah metode diskusi, presentasi dan berbagi informasi. Penulis menyimpulkan bahwa kegiatan perkuliahan tidak efektif, sehingga jika terus dibiarkan tanpa ada perbaikan maka dikhawatirkan hasil belajar mahasiswa menjadi tidak memuaskan serta kualitas pembelajaran menjadi buruk.

Dampak lebih lanjut adalah informasi yang ada selama perkuliahan akan tidak diserap dengan baik oleh mahasiswa karena mahasiswa mendapatkan pengalaman belajar yang tidak sesuai dengan harapan mereka.
Untuk itu, penulis mencoba untuk melakukan inovasi di ruang kelas tersebut pada saat perkuliahan berlangsung. Berdasarkan hasil studi literatur maka penulis mendapatkan inspirasi untuk menerapkan metode permainan dalam perkuliahan. Metode permainan yang diterapkan merupakan serangkaian bentuk pembelajaran yang berbasis permainan di ruang kelas selama perkuliahan berlangsung. Permainan tersebut berbeda jenisnya setiap kali pertemuan. Tujuannya adalah agar mahasiswa tidak menjadi bosan.

\section{METODE PENELITIAN}

Penelitian ini adalah penelitian tindakan kelas, dimana siklus terus dilaksanakan sampai akhir perkuliahan. Perbaikan setiap siklus adalah dasar pemilihan jenis permainan untuk pertemuan berikutnya. Penelitian dilaksanakan selama perkuliahan semester Januari-Juni 2016. Subjek penelitian ini adalah mahasiswa program studi Biologi 2013.

\section{HASIL DAN PEMBAHASAN}

Hasil pengamatan terhadap aktifitas mahasiswa selama perkuliahan dapat dilihat pada Gambar 1. 


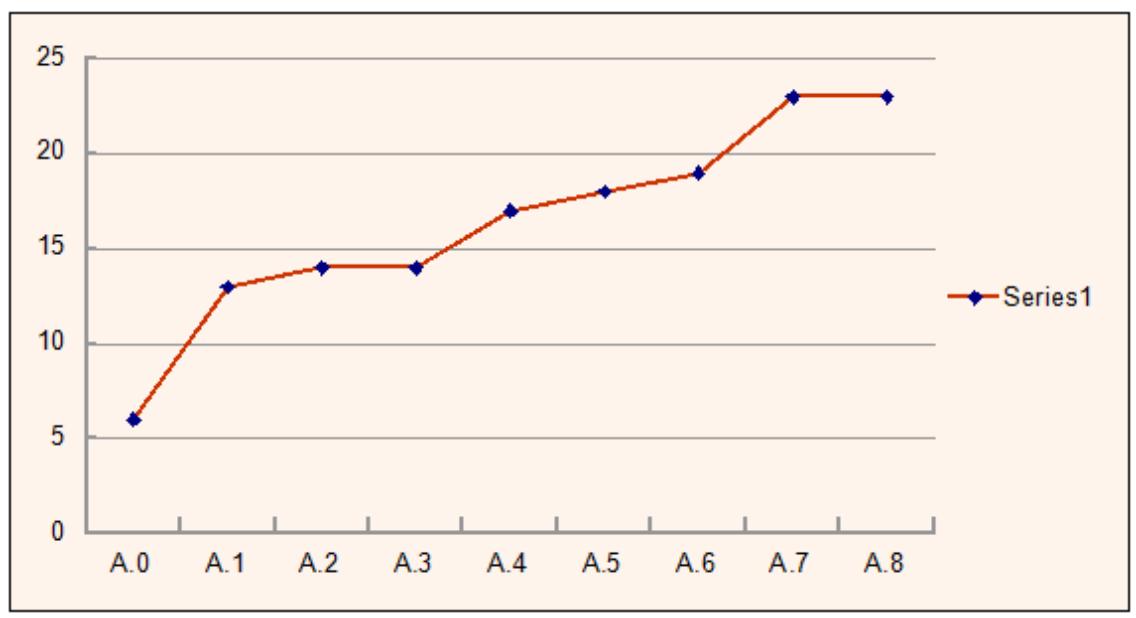

Gambar 1. Frekuensi Aktifitas Mahasiswa

Berdasarkan gambar pada grafik terlihat bahwa peningkatan frekuensi aktifitas mahasiswa pada perkuliahan dengan menggunakan metode permainan. Pertumbuhan dimulai dari angka 5-10 orang pada awal pengamatan, sampai dengan 20-25 pada akhir pengamatan. Pertumbuhan ini menunjukkan bahwa jika dipandang dari sisi aktifitas mahasiswa, maka metode permainan memiliki efek positif untuk memperbaiki kualitas pembelajaran dengan meningkatkan frekuensi aktifitas mahasiswa. Metode permainan tidak hanya menarik bagi anakanak namun juga bagi orang dewasa pada pendidikan tinggi (Paiva, 2016).
Aktifitas yang dimaksud dalam penelitian ini adalah semua aktifitas yang menjadi pendukung terlaksananya perkuliahan yang baik. Aktifitas yang diamati tersebut antara lain adalah menanya, menjawab, memberikan pendapat, menambahkan jawaban dan menyimpulkan materi. Aktifitas mahasiswa dapat meningkat dikarenakan mahasiswa termotivasi untuk belajar dengan menggunakan metode permainan ini (ChaoFernandez, 2016)

Sebaran hasil belajar mahasiswa setelah perkuliahan dengan menggunakan metode permainan dapat dilihat pada Gambar 2. 


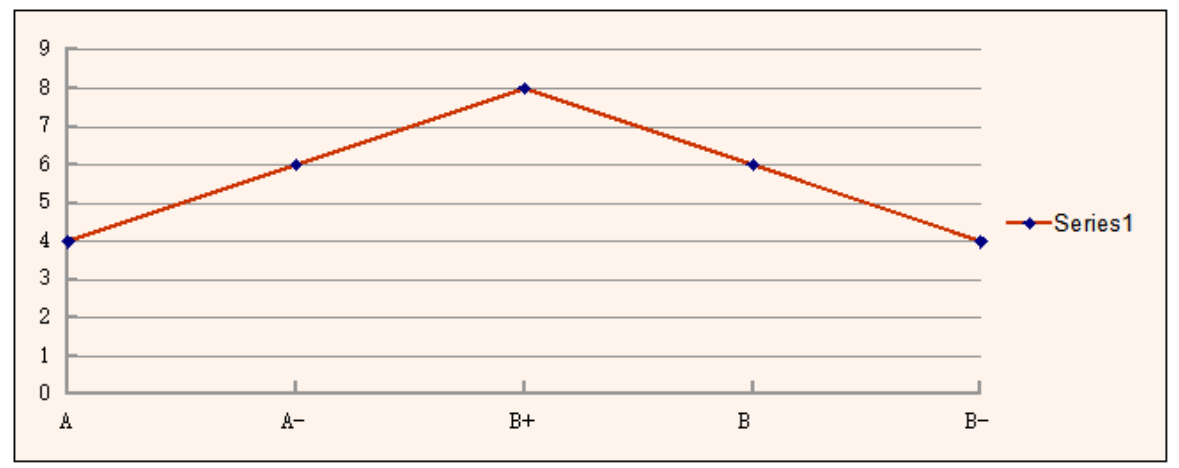

Gambar 2. Sebaran Hasil Belajar Mahasiswa

Gambar 2 menampilkan hasil belajar mahasiswa setelah dilaksanakan perkuliahan dengan menggunakan metode permainan. Rentang nilai yang diperoleh mulai dari Bsampai A. Mahasiswa yang memperoleh nilai B- berjumlah 4 orang, B berjumlah 6 orang, B+ berjumlah 8 orang, A- ada sebanyak 6 orang dan A sebanyak 4 orang. Hasil ini menunjukkan bahwa metode permainan memberikan dampak positif untuk menjadikan hasil belajar mahasiswa menjadi baik.

\section{KESIMPULAN}

Penelitian yang telah dilakukan memberikan informasi kepada pembaca bahwa metode permainan dapat meningkatkan hasil belajar mahasiswa secara signifikan dan sebaran hasil belajar yang baik saat metode ini telah selesai dilaksanakan.

Peneliti berharap agar penelitian ini menjadi bahan bacaan yang baik sehingga akan menambah kekayaan dunia pengetahuan secara umum, dan dunia pendidikan secara khusus.

\section{DAFTAR PUSTAKA}

Paiva, Ana C.R, et all. 2016. iLearn-Test Framework For Educational Games. Procedia-Human and Social Sciences. 21-23 June 2016.

Chao-Fernandez, Rocio, et all. 2016. Analysis of The Use of ICT Through Music Interactive Games as Educational Strategy. Procedia-Human and Social Sciences. 15-17 June 2016. 